\title{
Taking stock after a decade: Does the 'thresholds of potential concern' concept need a socio-ecological revamp?
}

\author{
Authors: \\ Harry Biggs ${ }^{1}$ \\ Sam Ferreira ${ }^{1}$ \\ Stefanie Freitag-Ronaldson \\ Rina Grant-Biggs ${ }^{1}$ \\ Affiliations: \\ ${ }^{1}$ Scientific Services, South \\ African National Parks, \\ Skukuza, South Africa \\ Correspondence to: \\ Harry Biggs \\ Email: \\ biggs@sanparks.org \\ Postal address: \\ Private Bag X402, Skukuza \\ 1350 , South Africa \\ Dates: \\ Received: 10 May 2010 \\ Accepted: 01 Oct. 2010 \\ Published: 13 May 2011 \\ How to cite this article: \\ Biggs, H., Ferreira, S., \\ Freitag-Ronaldson, S. \& \\ Grant-Biggs, R., 2011, \\ 'Taking stock after \\ a decade: Does the \\ 'thresholds of potential \\ concern' concept need a \\ socio-ecological revamp?', \\ Koedoe 53(2), Art. \#1002, 9 \\ pages. doi:10.4102/koedoe. \\ v53i2.1002
}

(C) 2011. The Authors. Licensee: OpenJournals Publishing. This work is licensed under the Creative Commons Attribution License.
The concept of thresholds of potential concern (TPCs) as implemented for the last decade in strategic adaptive management in South African National Parks (SANParks), has proved workable in practice in a number of instances, but in others appears beset by conceptual and practical limitations or barriers. Three common challenges relate to (1) situations where there is uncertainty about whether and where real thresholds exist, (2) whether and how preferences and other social constructs, as opposed to what were seen as objective biophysical variables only, can be used for TPCs and (3) whether it is admissible to adjust TPCs to allow for variations in societal behaviour, in particular rate of management response. All three challenges arise in the face of TPC objectivity implied by the original definition, and in the light of the original view that TPCs be set some distance prior to a presumed ecological threshold.

This paper suggests that the three challenges can be partly or largely dealt with by the use of a wider socio-ecological view, rather than seeing TPCs in isolation or as being only biophysical. Also, while detection of abrupt changes is helpful, it makes little practical difference if some TPCs happen to describe linear processes. The very decision to intervene can induce an abrupt change. Once a wider socio-ecological approach is employed, it becomes necessary for the user to specify the particular usage envisaged for the TPC, for instance, whether it is considered a preference and whether that preference is believed in any way to be related to an ecological threshold. In all cases, it is recommended that some form of explicit representation of the socioecological view is constructed - we suggest a cause-and-effect diagram (and give an example generated through a thought experiment) which describes presumed relationships in the subsystem of interest. This provides a broader systemic context and a shared understanding, and has implications for considering scenarios and management alternatives. For practical reasons, from the several states and processes in such a subsystem, only a few links can be chosen on which to base particular TPCs. If we have understood the subsystem well enough, these few links, at each of which a TPC is developed, will act as diagnostic points at which we can monitor the performance of the subsystem adequately. A broadened definition of a TPC is presented, supporting this approach.

Conservation implications: The concept of thresholds (initially ecological thresholds) has started influencing conservation management practice, a commonly-used formulation for management decision-making being the threshold of potential concern (TPC). Practical TPC usage can often be improved by moving away from its initially pure ecological outlook, rather framing understanding through an interlinked socio-ecological view.

\section{Introduction}

Strategic adaptive management as an operating philosophy (see Roux \& Foxcroft 2011) has attracted wide interest in South Africa. It spread from its original usage on river issues in and around the Kruger National Park (Biggs \& Rogers 2003) to a wide range of other biophysical themes associated with national parks elsewhere in the country and more generally, to natural resource management issues such as integrated water resources management (Freitag et al. in press). One central construct which has attracted interest is that of thresholds of potential concern (TPCs; Biggs \& Rogers 2003). The current application of TPCs equates to 'decision thresholds' sensu Martin et al. (2009), but ones which specifically presage predicted ecosystem thresholds. These authors also define such 'ecological thresholds', as well as another category, 'utility thresholds', which are value-based ones, giving high leverage if acted on. The Strategic Adaptive Management approach in which TPCs are embedded assumes an often-changing context in which resource management is taking place. The approach thus strives to take a modest position, and to inculcate assertive learning-by-doing in what is seen as a complex world (sensu Levin 1999) in which surprises occur. The original concept of TPCs (Rogers \& Biggs 1999) hinged on upper and 
lower limits of a variable of interest in the ecosystem, being set with the idea of allowing management some time to respond, before the expected ecosystem threshold was crossed. This therefore carries the challenge of predicting or anticipating an ecological outcome via knowing, or at least being able to hypothesise, an approximate ecological threshold (Martin et al. 2009). Nevertheless, even if a state change is predicted, the approach does not always link the TPC to the hypothesised mechanisms of change explicitly (see Ferreira et al. 2011) and may thus be less useful to management than if the cause of change is known.

TPCs were originally seen as flowing from high-level vision and objectives, forming 'low-level goals ... provid[ing] managers on the ground with targets of ecosystem condition ... scientifically rigorous, spatially and temporally bounded... act[ing] as amber lights to warn managers of possible unacceptable environmental change'; in practice being 'upper and lower levels of change in selected biotic and abiotic variables which act as indicators of the acceptability of ecosystem condition' (Rogers \& Biggs 1999). It should be noted that this definition obviously does not preclude ongoing management, although imminent or actual TPC exceedance will always lead to consideration of an important additional management response. This usage has, apart from a few attempts to recommend it in other contexts (e.g. when wilderness qualities were perceived to be dropping below an acceptable level [South African National Parks (SANParks) internal communication, Freek Venter] and for tourism standards and resource use guidelines, in a few postgraduate studies), been limited to biophysical issues, and mostly these have been viewed one at a time. This has led to some progress, some frustration and some learning (Van Wilgen \& Biggs in press; Gaylard \& Ferreira 2011). The progress in certain theme areas, such as river management and fire management, has been held up as an example for possible use in other theme areas, according to Biggs et al. (2011). However, these authors point out that there is too little deeper reflection generally associated with the use of TPCs, and that when such reflection does take place (as it did in the fire and river examples they describe), it enables a fuller and more productive adaptive cycle to occur.

Even though TPCs play this catalytic role in enabling these adaptive loops to be closed, there are several conceptual obstacles now evident after more than a decade of use of TPCs in the institutionalised way described by Biggs and Rogers (2003). Ferreira et al. (2011) and Gaylard and Ferreira (2011) address several issues around emergent TPC usage, such as the fact that they are less successful if the underlying hypothesised mechanisms are not explicitly articulated. For instance, it hardly helps to have a TPC for unacceptably reduced river flow if one cannot understand what drivers (e.g. increased abstraction) are leading to this, or what worrying consequences (e.g. increased sedimentation) are likely. Such explicit articulation is now undertaken in joint science-management discussions, which slows down the process, but results in the building of a more strongly shared rationality and thus carries wider organisational support than before. The joint hypothesising of such mechanisms, within the context of a socio-ecological system, also helps to link the objectives with the actual monitoring decisions more effectively, especially since it is not possible to monitor all the links and there is seldom one single 'correct' variable, or group of variables, to monitor in a complex system (Stirzaker et al. 2010). Also, many parks are, because of their need for rehabilitation, lying largely outside the desired state, sensu Roux and Foxcroft (2011). A wider formulation of the systemic context in which the TPCs are embedded (i.e. a richer and broader picture of the way the system appears to function) assists in helping understand the manner and pathway through which restoration might best be applied. Designing TPCs to focus on processes and/or on rate changes, and not only on outcomes, would be make them even more useful, but this is very challenging, partly because of lack of detailed understanding of these processes.

In this paper, we attempt to respond to several recurring conceptual issues that appear to act as dampers to the use of TPCs:

- There is often uncertainty as to whether a real threshold even exists, and if so, where exactly it lies. This makes TPC developers and users hesitant, given the certainty they may originally have expected TPCs to deliver. Hesitation also occurs when they suspect that a process is linear, or for any other reason, is believed not to have a clear threshold.

- There is a feeling that even if a functional biophysical threshold exists (say a point after which so many large trees, ostensibly acting as nutrient pumps, disappear from a landscape, that its nutrient status quickly changes), it is perceived to be easier in some cases to set TPCs as human preferences (e.g. there are fairly clear preferences for large trees in open savannas [Herbert Prins, unpublished data]). Similarly, scientists and managers in SANParks, although often suggesting that the threshold concept would be useful for pure economic or sociological (say tourist perceptional) phenomena, have in practice invariably not gone ahead and developed and implemented these in the way that has happened with biophysical ones. We speculate that this hesitation is partly because of perceived vagueness of these compared to the perception of 'hard biophysical' TPCs, even though preferences (such as for large trees in savannas) may often be expressed rather precisely. This hesitation to develop social TPCs may be related to the popular, yet flawed, perception that ecology is largely an exact science and/or to the uncertainty and associated lags resulting from the biophysical interacting with the social domain (such as delays in decision making or implementation). Shortage of capacity to formulate these social and economic TPCs (as opposed to the more capacitated biophysical science division) has also been cited as a contributing reason for their absence in SANParks management plans.

- There is uncertainty, if levels of TPCs are adjusted to give for example, slower responding management systems enough chance to still react in time, whether this constitutes a breach of their objectivity. 
In an attempt to find a basis from which to deal with the above obstacles, we will use the term 'limit' to refer to what is generally considered an unambiguous change, such as cessation of surface flow in a perennial river. We sometimes use 'boundary' (rather than threshold, since this paper deals with a potential widened meaning for TPCs) to refer to the transition at which a generally clearly acknowledged change of state occurs, such as from an open grassland to a thicket, or from a state-operated model to a concessioned model (for example, a tourism facility in a park). We recognise what we will call 'preferences' along a gradient of continuous change, often not associated with a boundary or biophysical limit. We distinguish 'preference' from, or at least recognise that it grades into, 'acceptability' the latter implying something closer to non-negotiable, a feature some users originally may have implicitly attributed to TPCs, even though clear processes of TPC revision (Rogers \& Biggs 1999) were described because it was anticipated they would be required often.

We address these barriers explicitly and thus ask three questions, (1) how can we overcome the damper which arises because of uncertainty about whether a threshold exists and where it lies, (2) can TPCs be used for preferences and (3) can TPCs be adjusted to take embedded human behaviours, especially in the rate of institutional responses, into account? We then propose a TPC revamp that easily accommodates several biological and cultural concerns and perceptions inherent in socio-economic-ecological systems that are an intrinsic part of conservationists' mandate as expected by society.

\section{Dealing with the barriers}

\section{Taking decisions and action in spite of uncertainty about a threshold or a limit}

Managers cannot afford to be paralysed by uncertainties. In fact, adaptive management makes much of moving forward by conceptualising and probing the system intelligently and thus 'reframing the problem in a way that gives a place to stand and take action while we learn more about how the system is really operating' (Stirzaker et al. 2010). Rather than following the cue arising from the very common cautiousness of scientists (who often recommend waiting until more evidence is available before making a decision), generally adaptive management encourages us to move forward by making a decision, though this should be balanced with some slowness to enable appropriate stability and reflection (Cilliers 2006). This decision-making imperative should include the possibility of an explicit, well-considered, 'noaction-now' management decision being taken. Importantly, this differs from the conventional 'wait-until-more-evidenceis-available' approach, in that it and all other options and their anticipated consequences have been concurrently evaluated and the 'no-action-now' decision taken as the best option. Since such a decision is then as valid as any wellreasoned decision that drives immediate action, decisionmakers should not feel they have not taken a decision simply because there has been no immediate resultant physical action on the ground.

Current biophysical TPC s can be seen as lying on a continuum of 'empirically well or fairly well understood' through an intermediate position 'informed by expert opinion' right down to 'intelligent early guesswork' (see also Gaylard \& Ferreira 2011). This spectrum would likely also apply when TPCs are more widely used for social and economic variables. When a large proportion of TPCs are associated with intermediate and higher levels of inherent uncertainty, our observation is that this tends to disturb and even paralyse potential adaptive management practitioners. This caution is understandable, but also needs to be overcome if progress is to be made in adaptive management. This is particularly so because of the trade-off between encouraging and allowing systems to vary a sufficient amount within the 'tent of acceptability', that is, the envelope representing the desired state, to promote resilience, and the need to yet respond in time, so as not to land up on an undesired trajectory outside this envelope (see Figure 1). The level of risk tolerance as opposed to risk aversion, (the so-called 'risk appetite'), therefore plays an important role in how conservationists constrain that envelope of acceptable variability. The level at which they decide on their attitude to risk in different situations is thus pivotal. For instance, practitioners who regularly invoke the Precautionary Principle (Cooney 2004) but in a traditional sense, run the risk of reacting too soon and attempting to constrain the ecosystem by not allowing it to vary and develop resilience. Much of the critique of earlier management in the Kruger Park (in Du Toit et al. 2003) rests on the idea that managers had tried to hold the system relatively constant in time and space because of a belief that allowing great fluctuations was inappropriate. Applied with differing sets of values in isolation, the Precautionary Principle can also provide fuel for seemingly well justified but opposing management recommendations, as documented in an Australian example (http://www.acat.act.gov.au/ decisions.php?action=decision\&id=29). However, modern application of the Precautionary Principle (Cooney 2004) suggests acknowledgement of full societal context including societal values guiding objectives, which can include a belief in the value of allowing 'healthy' amounts of variation in the ecosystem and concurrent use of adaptive management feedbacks. The application of TPCs is consistent with this newer approach, which we suggest needs to be even more cognisant of development of tools such as TPCs. TPCs together define the outline of a desired state (Figure 1), derived through an adaptive planning process (see Roux \& Foxcroft 2011) which defines a vision and hierarchy of objectives which explicitly capture and express societal values and expectations. In essence, thus, ecological TPCs are determined by human values and expectations, but guided by known or presumed biophysical limits. Using TPCs, the full set of adaptive management steps are designed to then help take the most appropriate decision for implementation in this milieu of uncertainty, and to learn and change effectively as one progresses. 


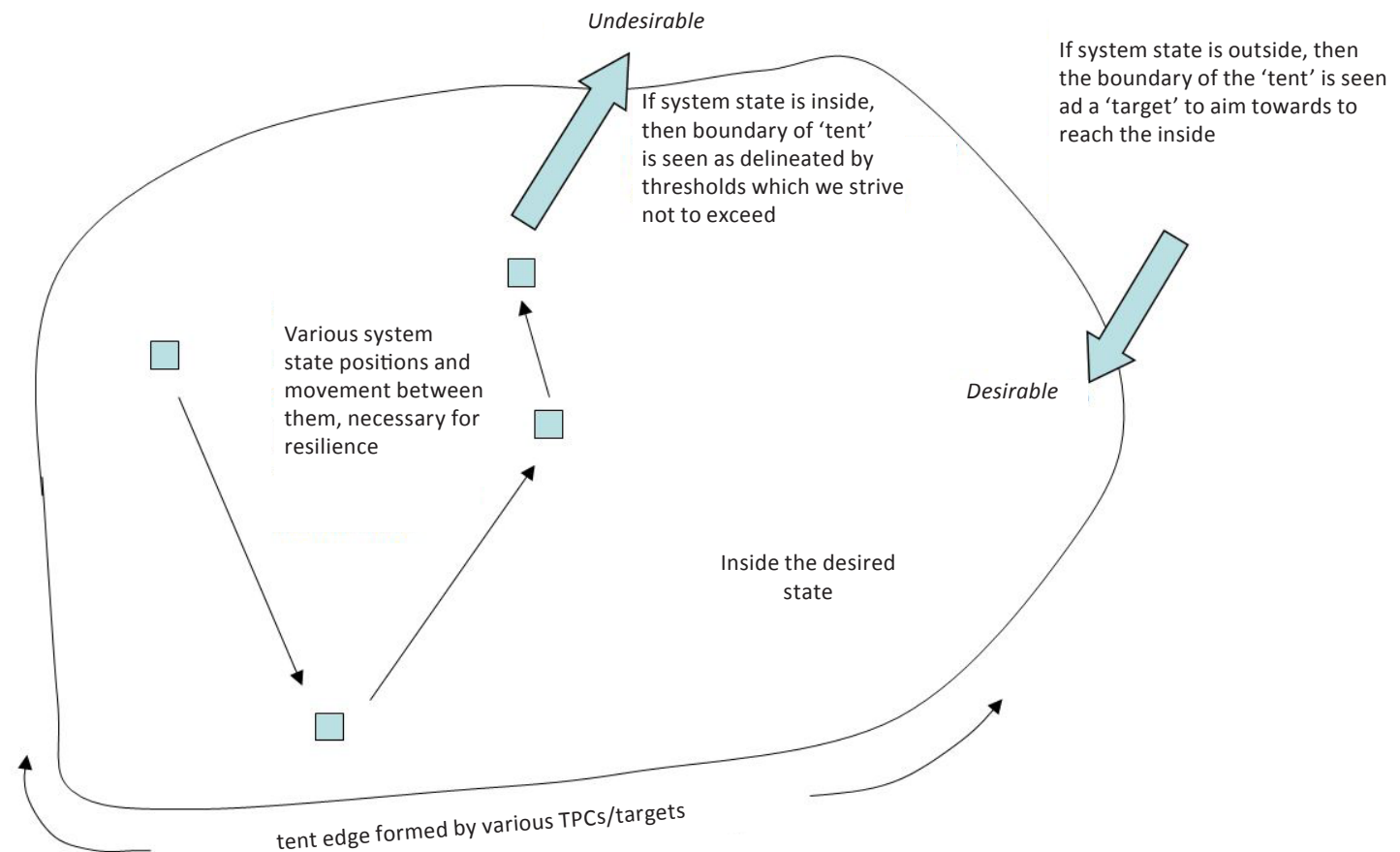

Outside the desired state

A 'tent of acceptability' is in reality a multidimensional cloud. Its boundaries are determined by the various thresholds making up the full suite used in that particular national park, protected area or situation.

If a system is already outside the 'desired state' the tendency is to call the threshold a 'target' as conservationists are aiming to 'get back inside the desired state'.

The level of risk tolerance, coupled with need for sufficient variation to build resilience, influences the size of the tent or cloud.

FIGURE 1: Two-dimensional schematic of the 'tent of acceptability' or 'desired state envelope'.

Wehave thus argued that adaptive management methodology places a premium on making decisions at various levels of uncertainty, usually then eliciting probing actions which help develop understanding of complex systems, but that there is also sometimes place for a well-reasoned 'no-actionnow' decision. Modern interpretations of the Precautionary Principle support this complex systems view, and depending on context, can address greater levels of risk than previously. Strategic adaptive management effectively incorporates value considerations in its fundamental planning phase, recognising that these, together with understanding of biophysical limits, underlie most TPCs in current use. Arguments presented below on incorporation of social preferences constitute important further reasons why decision-makers should not be paralysed by uncertainty concerning actual limits.

\section{Can thresholds of potential concern be used to describe, or can they include, societal preferences?}

We could argue that this is a non-question, given that the biophysical TPCs, although influenced by absolute limits, are also a form of societal preference. However, the question is so often asked in this form (and the expression to date of TPCs, has been in terms of biophysical variables) that we feel that it has been useful to retain it as the obvious entry point for those asking it. A better formulation for future use might be 'can social or biophysical descriptors qualify equally validly for societal preferences as embodied in TPCs?' Strategic adaptive management is rooted in human values as a basis for deciding on the desired state (Roux \& Foxcroft 2011) which is described in joint social and ecological terms (Walker \& Salt 2006). One component is a 'healthy' biophysical system, where 'healthy' is deemed in accordance with these values. A commonly depicted intersection of social (including economic) and biophysical facets (Figure 2) suggests that the desired state can most productively be seen as the socially and biophysically desirable and sustainable overlapping area. Again, 'biophysically sustainable' refers to absolute physical limits, but also to considerations of human acceptability and even preference. So again, in spite of the fact that both circles involve human choice, we find the figure useful as an entry point, the target of the biophysical one being expressed in biophysical terms. The overlap in Figure 2 requires the context, if not the definition, of a TPC to be expanded beyond only addressing the biophysical subsystem. It can still be useful to have definitions for TPCs in pure biophysical or social subsystems, but these must then be viewed as parts of the joint system.

A common debate in SANParks is about the introduction of the 'big 5' (elephant, rhino, buffalo, lion and leopard) into smaller, usually recently proclaimed, parks. This is usually justified on the basis of both restoring natural biota and processes, and presumed attractiveness to tourists. Statements which can be quoted as supporting this are often 


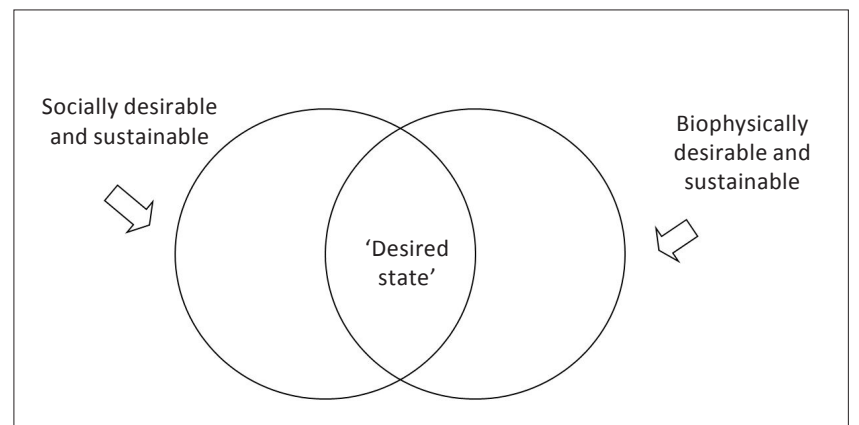

An argument can be made for the overlap zone being the only truly sustainable zone. The biophysical domain is shown separately because it has been seen historically as such, even though what is biophysically desirable is simply a subset of what is socially desirable. Not all socially desirable and apparently socially sustainable choices will necessarily be biophysically sustainable, though ultimately, if society takes the longer and more inclusive view, they should be.

FIGURE 2: Desirable and sustainable biophysical and social domains, and the overall 'desired state' in their overlap zone.

available in the vision and objectives of the specific park's management plan, which will have been drawn up, in line with the National Environmental Management: Protected Areas Act (Act no. 57 of 2003), in a stakeholder-centred way. Contention that has arisen around such introductions (for instance, damage to adjacent livestock from escaped predators) is in several cases not well resolved, and flags the need for more holistic and nuanced guidance in the higherlevel processes (such as derivation or prioritisation of the park mission and objectives) which provide guidance for such decisions. Without going into how this is being addressed by SANParks, and without specifying any particular park, we create here a plausible but fairly generic 'thought experiment' in which one set of possible outcomes of such decisions, as they might currently be made, could play out when viewed as an interacting socio-ecological system. The purpose of doing this is to illustrate that social and ecological TPCs interact, and are usefully viewed as a joint system, actually necessitating the incorporation of social TPCs. We use the kind of cause-effect diagram that might be produced by a park science-management forum at SANParks, without adhering to the full rigour and strict conventions of a formal influence diagram.

The particular cause-effect diagram in Figure 3 has three vertical threads, depicting outcomes for tourism, ecological condition and neighbour relations. The heart of the diagrammatic narrative shows a positive or reinforcing feedback loop between increasing possibilities for elephant viewing in the park, and tourism-derived income. In this particular story, only those negative (dampening) feedbacks which later on influence tourism income in some way (resultant problems with trail camp accommodation, unacceptable tourist-elephant conflict and ultimately, loss of viewing opportunities due to a mass decline of elephant following a severe drought) manage to start slowing down the major reinforcing loop which initially governs park decisionmaking in this hypothetical narrative. Potential feedbacks about other concerns covered in SANParks' mandate (habitat condition, access to tourism by lower/middle income locals, and costs borne by neighbouring communities) are, in this particular scenario, all insufficiently strong to reverse that central trend. Obviously we could continue by exploring what might happen if those currently 'dead-end' options became stronger (producing their own effective feedbacks), and develop by similar thought experimentation further illustrative narratives with their own cause-effect diagrams. In fact, the elephant ecological impact TPC, which is treated, for reasons of clarity of the overall story, as a single item in the figure, unpacks in practice into a whole diagram of its own, currently in use in various forms in SANParks. The point is that whatever diagrams are deemed necessary by a science-management forum (the normal vehicle to discuss such issues in the SANParks case) should be drawn. Figure 3 should be adequate to illustrate why such an approach is useful, if not essential. It provides the backdrop of systemic understanding for the justification and positioning of TPCs. That systemic understanding, represented by the diagram as a group mental model, is thus jointly agreed on, at least by the participants, bearing in mind that they also bring with them wider stakeholder impressions from frequent interactions with these groups, some of these interactions being mandatory for park plans. Figure 3 also hypothetically lists the most likely TPCs which might be used, and illustrates why both social and biophysical TPCs are essential if a holistic understanding is to be obtained. It also lists a host of other potential TPCs which could be used in a world with limitless capacity. There is an art to selecting a few particular ones, from all the possible ones which could be thought of, enough to give a fair chance of an overall understanding of the system, but not so many that the associated development, monitoring and interpretation activities become overwhelming. We need to remember that a diagram of the kind shown in Figure 3 would constitute only one of several, and possibly in a large or complex park, up to perhaps 15 cases. Each diagram will have associated TPCs. Even given that several of the same TPCs occur in different diagrams (in other words, in different theme areas), the overall capacity to develop TPCs, monitor, manage and reflect, remains finite, and a parsimonious but effective set needs to be chosen.

While there is some evidence that ecosystem changes might often (but certainly not always) take the form of thresholds (Schröder et al. 2005), these are invariably connected to social changes (Resilience Alliance \& Santa Fe Institute 2004) which are underlaid by values, the results of these value shifts often leading to fairly abrupt change (as in a ban on smoking). We thus need to become equally comfortable with the fact that many of these social (including economic) changes can also have a threshold nature - such as changes in fashion, and financial collapses (Scheffer 2009). However, the issue of linearity compared to non-linearity has probably caused unnecessary confusion in the implementation of TPCs to date. In any system with feedbacks causing movement across a boundary, even if some of the changes are linear, there could be a state change of interest to natural resource or park managers. If there is no state change, or if the change is linear, predictable, and especially if it is reversible, then this (unusual) set of circumstances will be relatively 


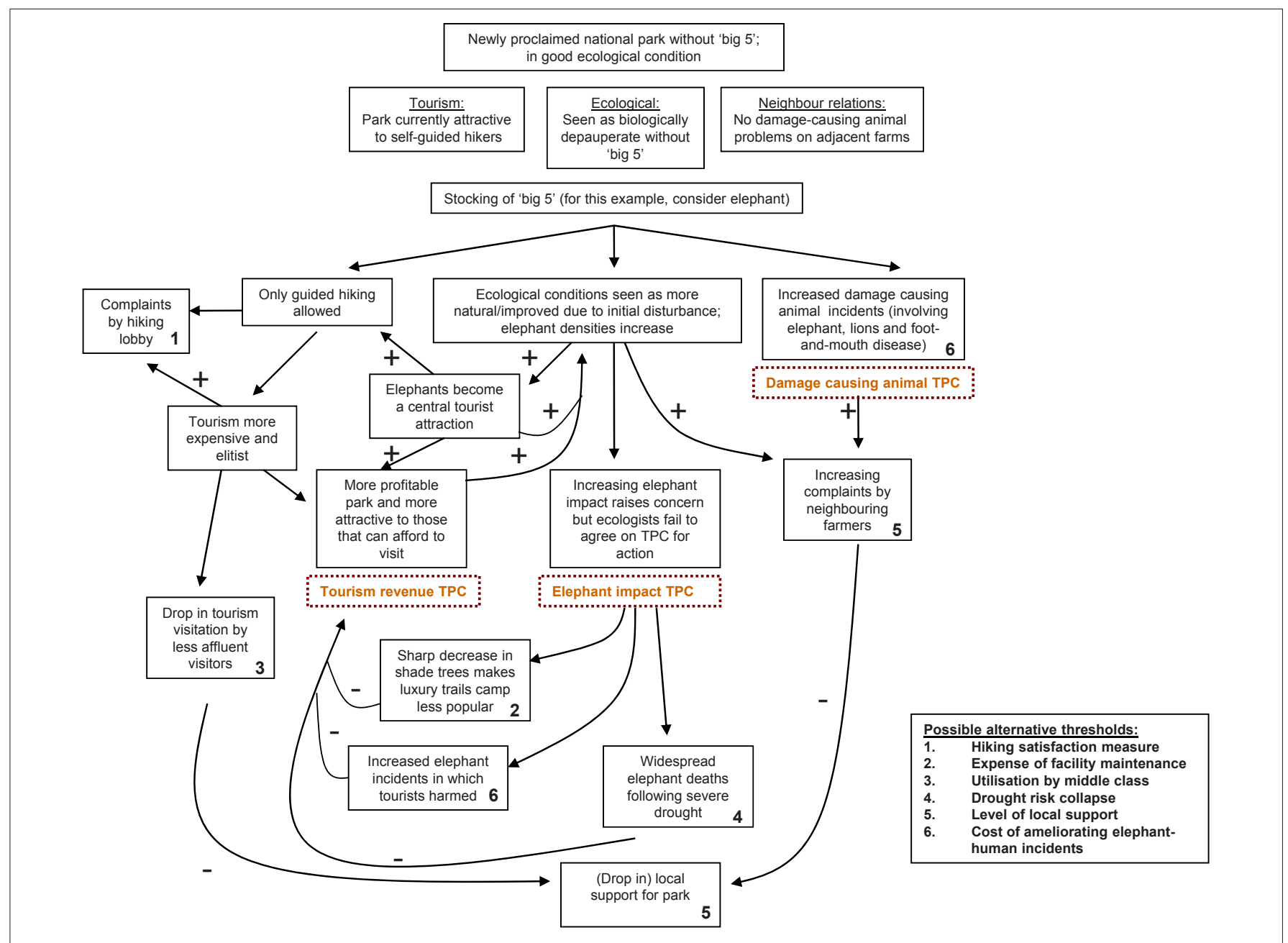

The scene is set at the top as a newly proclaimed park being stocked with the 'big 5 '.

There are three vertically arranged themes (tourism, ecological and neighbour relations).

+ , an increase in the factor featured in the box from which the arrow comes, causes an increase in the factor that is shown at the arrowhead; -, a decrease at the arrowhead's target factor. Boxes with dotted borders represent the three TPCs chosen for use in this hypothetical example.

Boxes numbered 1-6 represent several other possible TPCS not put into use because of capacity limitations.

FIGURE 3: An illustrative cause-and-effect diagram showing how inter-related social and biophysical themes are a typical issue in park management.

straightforward for management to handle. Our interest therefore focuses on the more frequently occurring (often non-linear) tenacious state changes in which one threshold (or more often, a series of interlinked thresholds in a coupled sequence as in Figure 3) can change. This is loosely called a regime shift (Scheffer 2009): a relatively sudden jump from one dynamic regime to another, in which the interactions between the controlling variables (and therefore the explanatory diagram) usually alter. Certain of these regimes are desirable as judged by operative values, and others undesirable. When in a desirable one, management aims to maintain its 'healthy' state by allowing variation within it, but not allowing an undesirable trajectory to take the system outside of the limits.

One important sign of the system moving outside of the desired state is a consistent directionality until the next state is reached (Ferreira et al. 2011). Said another way, allowing this desired variation (inside the envelope, Figure 1) usually implies that net overall movement hovers around zero (i.e. in the 'ball-in-the-basin' metaphor, Walker \& Salt 2006). Conversely, management initiatives to move the system from an undesired state to get back within it, also implies directionality to achieve this (Figure 1). This was often referred to as 'back inside' or 'back to natural' in conservation circles and is formally restoration (Society for Ecological Restoration 2004), although recently there is increasing recognition of the need to sometimes create acceptable 'novel ecosystems' (http:/ / herenthereneverywhere.wordpress.com /2010/02/04/novel-ecosystems/).

Human needs and values are often central underlying drivers of these changes, with the biophysical changes, such as global temperature increase, often being inadvertent outcomes which then lead to many of the changes. The adaptive management framework (see Roux \& Foxcroft 2011) should thus clarify how exactly TPCs might work as both 'retainers' of a particular state and 'targets' to which to return (Freitag et al. in press).

Whether a boundary crossing is threshold or non-threshold in underlying nature, the TPCs should be reflective of the desired state and its inherent values. Although SANParks has made good progress (see Roux \& Foxcroft 2011) in making this connection, through use of adaptive planning, 
it is still grappling with this when underlying objectives requiring to be balanced, are only partly compatible, as in the example in Figure 3. In fact, the situation in the generic example in Figure 3 (and alternative scenarios which might arise if the 'dead-ends' become more influential) will in the opinion of the authors be highly influenced by determination of effective synergies and trade-offs at the level of organisational and societal values. Until this happens effectively, and even afterwards, we consider such causeeffect diagrams indispensible in the formulation of TPCs and in the management of such a situation.

Often an emergent slow variable, say poorer education over many years, can lead to gradually poorer service delivery. In natural resource management, this may manifest as a sudden shortfall in a crisis period, for example, during a cyclone or a drought. An important challenge resides in setting thresholds which link the focused sub-system to the slower variables operating on the overall socio-ecological system. This is important because slow variables may be difficult or impossible to measure, yet may irrevocably change the system. Slow variables may also be biophysical, sedimentation of rivers being a good example in rivers flowing through the Kruger National Park. Sedimentation is relatively difficult to measure, and its consequences could easily have taken Kruger Park management by surprise were it not for an intensive research programme which highlighted it by drawing systemic diagrams of the type we now use and recommend in this paper, and were it not for the linkage made between sedimentation and some faster-acting, more easily measured variables. In Figure 3, investigation may show that profitability TPCs could be used as an early warning system to detect if, and perhaps at what scales, slower variables (slow changes in ecological condition which lead, over decades, to a sudden major change) are changing in an undesirable direction.

The well-known history of elephant culling in Kruger National Park (Whyte et al. 1998; Van Aarde et al. 1999) serves as a further example of the interactions between biophysical aspects and societal preferences. The history details, from the date of its inception until it was stopped, what was perceived as a mechanistic effort at capping populations. This was to avoid passing a perceived biophysical threshold of ecological degradation (Van Wyk \& Fairall 1969), derived through use of the Precautionary Principle within the rangeland ecological paradigms in use at that time. This capping of populations had other unexpected biophysical effects, such as higher calving rates during the years of culling (Van Aarde et al. 2008). The overall system had in fact changed in a step fashion (sensu Scheffer 2009) as a consequence of the intervention, even if protagonists of culling felt that such a change was acceptable given what they were attempting to avoid. In broader perspective, the culling campaign led to an increase in social unacceptability over time, a de facto threshold, and to suspension of culling (Whyte et al. 1998) with consequent further elephant population growth (Young et al. 2009). The socio-ecological system had passed a boundary, having moved from a state of 'culling by technocrats, acceptable to society' to a state of 'no longer necessarily acceptable, suspend culling and rethink overall issue'. In retrospect, at park-level, the elephant impasse resulted in decision paralysis while parks authorities were required to collect more information and conclusive proof of habitat destruction. While this caused significant frustration among managers, the resultant 'slowness' (Cilliers 2006) has enabled a rethink of ecological paradigms (Gaylard \& Ferreira 2011). Nevertheless, now, 16 years after culling stopped in 1994, the originally predicted ecological thresholds have not been passed, except for concern around the TPC concerning reduction of large trees that has been tabled (SANParks 2009) and may lead to management aimed at reducing effects, possibly even culling (now legally allowable again; DEAT 2008), in at least some parts of the Kruger National Park.

We have stated that while a broader view is essential for contextualisation, it is not feasible to track the full suite of variables and links, and some focus on a key part is needed in the interests of practical expediency. Gaylard and Ferreira's (2011) unpacking of ecological concerns extended into the social realm, coupled with scenario evaluation and comparative risk assessment (see box in Gaylard \& Ferreira 2011), may actually help overcome parts of this challenge. An example is how conservationists may wish to manage elephant effects that range from ecological to societal (Scholes \& Mennell 2008). Unpacking these effects could help converge onto a common mechanism and driver of how elephants can cause ecological change, induce human conflict, enhance tourism experience and generate revenue (Gaylard \& Ferreira 2011) - in their analysis, spatial use by elephants turns out to be central. TPCs as originally formulated, akin to decision thresholds (Martin et al. 2009), will thus reflect modulators of elephant spatial use, while allowing the inclusion of utilitybased TPCs (Martin et al. 2009) and will embody a range of ecological, social, economic and financial contexts. Although it is useful to link these to actual ecological thresholds, we have learnt that restricting TPC usage to only this latter class is very limiting and has proved frustrating. Extending their usage to include societal preferences and take into account organisational and human behaviour in the ways described, and unpacking the real meaning of each, better supports how society influences how conservationists should act in their interest.

The narrative in Figure 3, and the potential other narratives that could unfold if the currently 'dead-end arguments' in Figure 3 were to gain sufficient momentum, demonstrate that even innocent-looking social choices can have very real consequences for the desired biophysical state in a conservation agenda. The viewpoint that humans can choose to carry out any of a range of activities on an ecosystem template that is generally in good shape, is correct. However, zooming in slightly, there are different possibilities in the specific mix of ecosystem services available, and these are of explicit management interest. For instance, predictions that the mopani vegetation type will expand under climate change (Rutherford et al. 1999) and perhaps later embrace all except the southernmost corner of Kruger National Park, will almost certainly lead to different tourist outcomes and experiences. We could argue that both mopani and what is left of the other habitats are fundamentally healthy, and similar social activities can be practised on both. But the way 
human values and park management might intersect with this projected outcome, leads to varying social trajectories (for instance, game-viewing tourism is popular along rivers in the mopani areas, but far less so away from rivers) and potential thought experiments which, like those in Figure 3, will illustrate how coupled and interdependent the subsystems are, and help avoid or navigate such change.

It is clear that much hinges on what is considered acceptable or preferred, or unacceptable and not preferred. This is broadly circumscribed during the adaptive planning process by the desired state (Roux \& Foxcroft 2011) which should have more appropriately been called the 'desired set of varying conditions' to reinforce the idea that systems tend to change all the time. What articulated desired states turn out to look like, and what is acceptable, are both fundamentally influenced by a variety of values, some of which are explicit and/or shared between stakeholder groupings (see SANParks [2008] for a set of explicit SANParks conservation values). It is well known that where there is a relatively high degree of sharing of values, societal preferences can more easily be defined and articulated, as for TPCs.

We thus feel that social TPCs should not only be allowed and encouraged, but that they are in fact essential (along with biophysical TPCs) if a full socio-ecological understanding is to be available as a basis for decision-making.

\section{Can thresholds of potential concern be adjusted to take embedded human behaviour, especially differences in the rate of institutional responses, into account?}

While remote ecosystems, almost uninfluenced by human events, can demonstrate naturally generated threshold events, almost all natural resource management situations in South Africa have fundamentally important social drivers and social outcomes. In virtually every case, various legislative and management authority mandates may also require contrasting outcomes, and a somewhat different culture and behaviour characterises each such authority. For instance, conservation and animal health legislation in South Africa may not have common outcomes (in the context of elephant management, see Scholes \& Mennell 2008). Even small differences in the biophysical situation can often reflect in some way the range of possibilities or outcomes in the social domain and vice versa. Resource management is typified by such partly competing, partly overlapping goals, and as holistic as possible an understanding is required to deal with this. TPCs developed in such a joint situation will need to reflect both cultures, or increasingly, a newly forged joint understanding and behaviour.

TPCs were originally defined as being some time before a 'real threshold' and so the question arises whether it would then be reasonable to set them more conservatively (i.e. to be exceeded even earlier) in a context where management responses might, for whatever reason, take longer. For instance, slower anticipated institutional responses in for example, one country compared to another. A rational empiricist might say this detracts from the objective setting of the TPC, because it takes into account the shortcomings of institutions and people, even though most will agree it is easier to change before, rather than after, a threshold is exceeded. For instance, degraded rivers are very difficult to restore; it is easier to keep a healthy river in a good state, irrespective of the institutional capacity that this requires in one catchment or country compared to another. However, making such an adjustment for capacity would seem to be consistent with, and even in support of, the logic describing the 'buffer' timing that should be considered in refining TPCs, according to Scholes and Kruger (2011).

\section{Towards a broader definition}

A re-orientation of the kind recommended in this paper may necessitate a revised definition of a TPC. We suggest 'any practical decision prompt based on a particular level (or upper and lower levels) of a social or biophysical variable which assists managers to avoid (or to transition into) a different state which is considered undesirable (or desirable). TPCs should not be seen in isolation, but as part of dealing with a complex socio-ecological system, and should be informed by biophysical limits in conjunction with human values'.

\section{Conclusion}

All three barriers described can be tackled by viewing the system in a wider context. TPCs are not isolated entities. They should relate to the broader subsystems, which often have social and biophysical interactions, in which they are embedded, and reflect the values and objectives comprising the desired state. The wider view is usually represented by a cause-effect diagram akin to the thought experiments presented here, and similar to what Gaylard and Ferreira (2011) use to help enhance TPC implementation. If it does not do so already, this should include the social domain, often manifest as preferences or as net economic effects which can be stated as acceptable thresholds. That will frame TPC usage explicitly in a coupled socio-economic-ecological context, where change in a single driver, or often a set of related cascading thresholds, leads to crossing of one or various overlapping boundaries, and thus to a regime shift (Scheffer 2009).

Until recently, most usage of TPCs has been geared towards a setting at least slightly before perceived ecological thresholds. Practitioners should be as plain as their knowledge allows them to be, about whether any of these are linked to thresholds or boundaries. If so, it seems entirely reasonable that the decision on how far before, might depend on the likely speed of response mechanisms, guided by principles described in Scholes and Kruger (2011) and that clearer management responses are enabled if the mechanisms causing change are explicitly hypothesised (Gaylard \& Ferreira 2011). Nevertheless, if it appears that the TPC is purely a preference, this should be stated in the supporting documentation, and where the link between a particular preference and any supposed real biophysical threshold is unclear, this should be noted and commented on, to assist future evolving development of the management system. 
Whilst we encourage wider socio-ecological contextualisation, it seems sensible when it comes to monitoring to rather choose key focus areas and track just those segments of the wider understanding. If objectives or drivers change, or if the variables followed are not adequate for the task, it may be necessary to expand or adjust these, probably within the framing of an adjusted cause-effect diagram.

Biophysical and social sciences are indispensable in helping understand the whole picture required for TPC formulation, and practitioners cannot be expected to understand the management meaning clearly, without some understanding of the pervasive inter-linkages between these. Such joint thinking should be encouraged right down to the operationally detailed components of park management plans. The commonality of joint mind-maps of socio-economic-ecological systems thus stretches across hierarchies of governance locally, provincially, nationally and internationally. The setting of thresholds is a means of checking to see if the originally jointly defined desired state (with its various objectives and goals) is maintained. This may include a variety of both qualitative (generally at entrylevel and then followed by increasingly building the rigour in the understanding) and quantitative TPCs (see also Gaylard \& Ferreira 2011). TPCs can only be practical if constructed, evaluated, adjusted and reacted upon within the context of human preference and behaviour.

If the changes suggested in this paper could be combined with refinements through approaches that capture a generality of TPC definitions as being process-orientated and recognising variability as a key outcome (Ferreira et al. 2011), and approaches that unpack key management concerns into cause-and-effect diagrams (Gaylard \& Ferreira 2011), then we may be entering the second and, it is hoped, more fruitful generation of TPC usage, and not restricted to only a moderate number of 'special' cases which appear to work well. A good opportunity therefore exists to write a unified set of guidelines collating these changes in approach and practical use.

\section{Acknowledgements}

We thank the many scientific collaborators, managers and rangers within SANParks for fruitful discussions over the years. These discussions have prompted ideas about conceptual and practical problems concerning TPCs and have led to the writing of this paper. Thanks also to Oonsie Biggs for insightful discussions and comments on an earlier draft of this paper, as well as to two anonymous reviewers whose comments and inputs have led to a more focused and tightened manuscript.

\section{References}

Biggs, H.C., Breen, C., Slotow, R., Freitag-Ronaldson, S. \& Hockings, M., 2011, 'How assessment and reflection relate to more effective learning in adaptive management', Koedoe 53(2), Art. \#1001, 13 pages. doi:10.4102/koedoe.v53i2.1001 Biggs, H.C. \& Rogers, K.M., 2003, 'An adaptive system to link science, monitoring and experience: Ecology and management of savanna heterogeneity, pp. 59-80, Island Press, Washington.
Cilliers, F.P., 2006, 'On the importance of a certain slowness. Stability, memory and hysteresis in complex systems', Emergence: Complexity and Organisation 8(3), 106-113.

Cooney, R., 2004, The Precautionary Principle in Biodiversity Conservation and Natural Resource Management: An issues paper for policy-makers, researchers and practitioners IUCN, Gland, Switzerland and Cambridge, UK.

DEAT, 2008, National Environmental Management: Biodiversity Act, 2004 (Act 10 of 2004): National Norms and Standards for the management of elephants in South Africa, Department of Environment Affairs \& Tourism, Pretoria, South Africa.

Du Toit, J.T., Rogers, K.H. \& Biggs, H.C. (eds.), 2003, The Kruger experience: Ecology and management of savanna heterogeneity, Island Press, Washington.

Ferreira, S.M., Deacon, A., Sithole, H., Bezuidenhout, H., Daemane, M. \& Herbst, M., 2011, 'From numbers to ecosystems and biodiversity - a mechanism approach to monitoring', Koedoe 53(2), Art. 998, 12 pages. doi:10.4102/koedoe.v53i2.998

Freitag, S., Biggs, H. \& Breen, C.M., (in press), 'Fifteen years of the spread and maturation of adaptive management in South African National Parks: organisational learning in systems perspective', in W. Freimund, S. McCool \& C.M. Breen (eds.), Engaging Complexity in Protected Area Management: Challenging Occam's Razor, University of KwaZulu-Natal Press, Pietermaritzburg, South Africa.

Gaylard, A. \& Ferreira, S.M., 2011, 'Modification and maturation of sanpark's adaptive planning process - making critical linkages between conservation objectives and actions', Koedoe 53(2), Art. 1005, 8 pages. doi:10.4102/koedoe.v53i2.1005

Levin, S., 1999, Fragile dominion: complexity and the commons, Helix Books, Boston.

Martin, J., Runge, M.C., Nichols, J.D., Lubow, B.C. \& Kendall, W.L., 2009, 'Structured decision making as a conceptual framework to identify thresholds for conservation and management', Ecological Applications 19(5), 1079-1090. doi:10.1890/080255.1, PMid:19688917

Resilience Alliance \& Santa Fe Institute, 2004, Thresholds and alternate states in ecological and social-ecological systems, 'Resilience Alliance (online)', viewed 15 April 2009, from http://www.resalliance.org/index.php?id=183

Rogers, K. \& Biggs, H.C., 1999, 'Integrating indicators, endpoints and value systems in strategic management of the Kruger National Park', Freshwater Biology 41, 439-451. doi:10.1046/j.1365-2427.1999.00441.x

Roux, D. \& Foxcroft, L.C., 2011, 'The development and application of Strategic Adaptive Management (SAM) within South African National Parks', koedoe 53(2), Art. 1049, 5 pages. doi:10.4102/koedoe.v53i2. 1049

Rutherford, M.C., Midgley, G.F., Bond, W.J., Powrie, L.W., Robert, R. \& Allsopp, J., 1999, South African Country Study of Climate Change. Plant Biodiversity: Vulnerability and Adaptation Assessment, pp. 1-59, National Botanical Institute Climate Change Group, Cape Town.

SANParks, 2008, Policy context: SANParks' mandate and values, chapter 2 of 'A framework for developing and implementing management plans for South African National Parks' viewed 15 April 2009, from http://www.sanparks.org/parks/ kruger/conservation/scientific/key_issues/plans/adaptive/pdfs/chapter_02.pdf

SANParks, 2009, Minutes of the Conservation Services Management Committee meeting, South African National Parks, Kruger National Park Archives, Skukuza on 02 April, 2009

Scheffer, M., 2009, Critical Transitions in Nature and Society, Princeton University Press, Princeton.

Scholes, R.J. \& Kruger, J.M., 2011, 'A framework for deriving and triggering thresholds for management intervention in uncertain, varying and time-lagged systems', Koedoe 53(2), Art. \#987, 8 pages. doi:10.4102/koedoe.v53i2.987

Scholes, R.J. \& Mennell, K.G. (eds.), 2008, Elephant management: A scientific assessment for South Africa, Wits University Press, Johannesburg, South Africa.

Schröder, A., Persson, L. \& De Roos, A.M., 2005, 'Direct experimental evidence for alternative stable states: a review', Oikos 110, 3-19. doi:10.1111/j.0030for alternative stable

Society for Ecological Restoration International Science and Policy Working Group, 2004, The SER International Primer on Ecological restoration. Version 2.

Stirzaker, R., Biggs, H., Roux, D. \& Cilliers, P., 2010, 'Requisite simplicities to help negotiate complex problems', Ambio 39, 600-607. doi:10.1007/s13280-0100075-7, PMid:21141779

Walker, B. \& Salt, D., 2006, Resilience Thinking: Sustaining Ecosystems and People in a Changing World, Island Press, Covelo.

Van Aarde, R.J., Ferreira, S.M., Jackson, T., Page, B., De Beer, Y., Gough, K., et al., 2008, 'Elephant population biology and ecology', in R.J. Scholes \& K.G. Mennell (eds.), Elephant management: A scientific assessment for South Africa, pp. 84-145, Wits University Press, Johannesburg, South Africa. doi:10.1111/j.1469-1795.1999. tb00075.x

Van Aarde, R.J., Whyte, I.J. \& Pimm, S.L., 1999, 'Culling and the dynamics of the Kruger National Park elephant population', Animal Conservation 2, 287-294.

Van Wilgen, B.W. \& Biggs, H.C., (in press), 'A critical assessment of adaptive ecosystem management in a large savanna protected area in South Africa', Biological Conservation. doi:10.1016/j.biocon.2010.05.006

Van Wyk, P. \& Fairall, N., 1969, 'The influence of the African elephant on the vegetation of the Kruger National Park', Koedoe 12, 66-75.

Whyte, I.J., Van Aarde, R.J. \& Pimm, S.L., 1998, 'Managing the elephants of Kruger National Park', Animal Conservation 1, 77-83. doi:10.1111/j.1469-1795.1998. tb00014.x

Young, K.D., Ferreira, S.M. \& Van Aarde, R.J., 2009, 'The influence of increasing population size and vegetation productivity on elephant distribution in the Kruger National Park', Austral Ecology 34, 329-342. doi:10.1111/j.14429993.2009.01934.x 